\title{
Rancang Bangun Sepeda Listrik 250 Watt Dengan Mengukur Kecepatan Dan Daya Baterai
}

\author{
Miftachul Ulum ${ }^{1}$, Mutiara Hikmah ${ }^{2}$, Achmad Fiqhi Ibaidillah ${ }^{3}$, Kunto Aji Wibisono ${ }^{4}$ \\ Teknik Elektro, Universitas Trunojoyo Madura ${ }^{1,2,3,4}$ \\ miftachul.ulum@trunojoyo.ac.id ${ }^{1}, 140431100002 @$ students.trunojoyo.ac.id ${ }^{2}$, fiqhi.badillah@trunojoyo.ac.id ${ }^{3}$ \\ kunto.ajiw@trunojoyo.ac.id ${ }^{4}$
}

\begin{tabular}{l} 
Article Info \\
Article history: \\
Received January $19^{\text {th }}, 2021$ \\
Revised January $28^{\text {th }}, 2021$ \\
Accepted May $26^{\text {th }}, 2021$ \\
\hline
\end{tabular}

\section{Keyword:}

Electric Bike

Speed,

Battery Power,

Proximity Sensor

\begin{abstract}
Electric bicycles are one of many vehicles with alternative fuels. This electric bike uses electric power as its power source. Whose electrical energy is converted into motion energy. To convert that electrical energy into motion energy is needed which is called an electric dynamo. The electric dynamo here becomes an engine core on an electric bike. The performance of electric bicycles is measured based on high power efficiency, low energy consumption levels and stable electric bicycle components in their use. To monitor the performance, a speed and battery power scrolling system was designed on a $250 \mathrm{~W}$ electric bike. An electric motorcycle is a type of vehicle consisting of brushless direct current $(B L D C)$ to move the wheel, controller as energy flow regulator on $B L D C$, and battery as a power source. The main parts of this monitoring system include two 12 volt batteries in the series, controller, BLDC, throttle, proximity sensor, liquid crystal display (LCD). Throttle works as a BLDC speed controller. DC power meter as a measuring detector for the amount of electric current, electrical voltage, electrical energy, and electrical power displayed on the $L C D$.
\end{abstract}

Copyright () 2021 Jurnal JEETech. All rights reserved.

\section{Corresponding Author:}

Miftachul Ulum,

Teknik Elektro, Universitas Trunojoyo Madura,

Email: miftachul.ulum@trunojoyo.ac.id

\begin{abstract}
Abstrak - Sepeda listrik adalah salah satu dari banyak kendaraan dengan bahan bakar alternatif. Sepeda listrik ini memanfaatkan tenaga listrik sebagai sumber tenaganya. Yang energi listriknya diubah menjadi energi gerak. Untuk mengubah energi listrik tersebut menjadi energi gerak dibutuhkan yang namanya dinamo listrik. Dinamo listrik disini menjadi sebuah inti mesin pada sepeda listrik. Kinerja sepeda listrik diukur berdasarkan effisiensi daya yang tinggi, tingkat konsumsi energi yang rendah dan komponen sepeda listrik yang stabil dalam penggunaanya. Untuk memantau kinerja tersebut maka dirancang sebuah sistem penggukuran kecepatan dan daya baterai pada sepeda listrik 250W. Sepeda motor listrik adalah jenis kendaraan yang terdiri dari brushless direct current (BLDC) untuk menggerakan roda, kontroler sebagai pengatur aliran energi pada BLDC, dan baterai sebagai sumber listrik. Bagian utama dari sistem pemantauan ini meliputi dua buah baterai 12 volt yang di seri, kontroler, BLDC, throttle, proximity sensor, liquid crystal display
\end{abstract}

(LCD). Throttle bekerja sebagai pengendali kecepatan BLDC. Power meter DC sebagai pendeteksi ukur besarnya arus listrik, tegangan listrik, energi listrik, dan daya listrik yang ditampilkan pada LCD.

\section{Pendahuluan}

Pada kondisi saat ini kendaraan bermotor menggunakan bahan bakar fosil tersebut yang meliputi bensin, solar dan gas. Dengan alasan itulah kendaraan bahan bakar alternatif adalah solusi dari permasalahan tersebut. Kendaraan aalternatif adalah kendaraan yang dapat beroprasi menggunakan bahan bakar selain bahan bakar fosil. Sebagai contoh kendaraan tersebut adalah kendaraan elektrik, hibrida dan kendaraann energy surya. Karana beberapa factor diatas, maka pengembangan kendaraan bahan bakar alternatif telah menjadi 
prioritas utama bagi pemerintah dan produsen otomotif di banyak Negara didunia terutama di Indonesia.

Sepeda listrik merupakan salah satu kendaraan dengan bahan bakar alternatif. Sepeda listrik memanfaatkan tenaga listrik sebagai sumber tenaganya. Energi listrik digunakan untuk diubah menjadi energy gerak. Untuk mengubah energy listrik tersebut menjadi energy gerak, dibutuhkan motor listrik atau sering disebut dengan dynamo listrik. Dynamo listrik ini menjadi sebuah inti mesin atau penggerak utama di sepeda listrik. Sepeda listrik tersebut sudah menjadi daya Tarik bagi masyarakat Indonesia. Sepeda listrik juga sudah diperjual belikan dengan harga yang cukup mahal. Banyak masyarakat Indonesia dan luar negri memakai sepeda listrik untuk kepentingan menempuh jarak yang pendek. Sehingga sepeda listrik sangatlah berguna untuk masyarakat.

Sepeda listrik adalah jenis kendaraan yang terdiri dari brushless direct current (BLDC) untuk menggerakan roda, kontroler sebagai pengatur aliran energi pada BLDC, dan baterai sebagai sumber listrik. Kinerja sepeda motor listrik diukur berdasarkan effisiensi daya yang tinggi, tingkat konsumsi energi yang rendah dan komponen sepeda motor listrik yang stabil dalam penggunaanya. Untuk memantau kinerja tersebut maka dirancang sebuah sistem pemantauan kecepatan dan pengelolaan baterai pada sepeda listrik $250 \mathrm{~W}$. besarnya arus listrik, tegangan listrik, energi listrik, dan daya listrik yang ditampilkan pada LCD. Lalu data yang ditampilkan pada LCD (liquid cristal display) secara real-time pada jenis lintasan jalan agar diketahui tingkat konsumsi daya listrik terhadap kecepatan sepeda motor listrik.

\section{Metode Penelitian}

\section{A. Metode}

Dalam penelitian ini ada beberapa langkah yang harus dilakukan sebelum benar - benar menciptakan sistem. Berikut adalah flowchart penelitian yang ditunjukan pada gambar 1 .

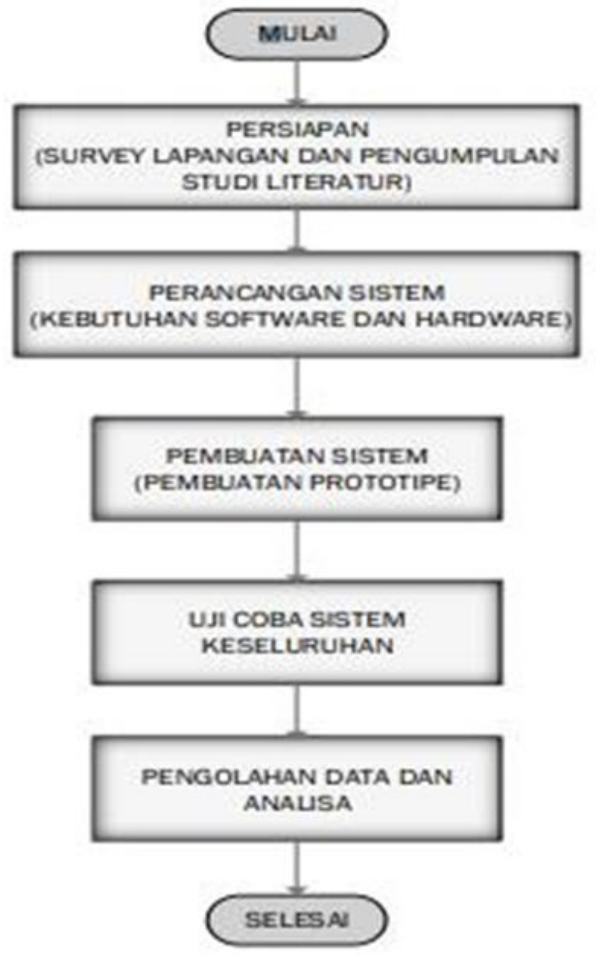

Gambar 1. Flowchat Penelitian

Dari Gambar 1 dapat dijelaskan bahwa pengerjaan penelitian ini diawali dengan tahapan persiapan yaitu tahapan pencarian data lapangan dengan melakukan survey secara langsung dan pengumpulan data melalui studi literatur. Tahapan kedua setelah semua data persiapan di dapatkan adalah tahap perancangan sistem yaitu tahap yang berisikan perancangan kebutuhan softwaredan hardware. Tahapan berikutnya adalah tahapan pembuatan sistem yaitu tahapan inti dimana penulis mulai membuat prototipe dan melakukan pemrograman software. Setelah prototipe dan software tercipta langkah selanjutnya adalah pengujian sistem secara keseluruhan mulai dari percobaan skala kecil hingga skala besar. Terakhir adalah pengolahan data hasil dari pegujian dan ditutup dengan analisa untuk mendapatkan kesimpulan.

\section{B. Perancangan Sistem}

Desain Alat 


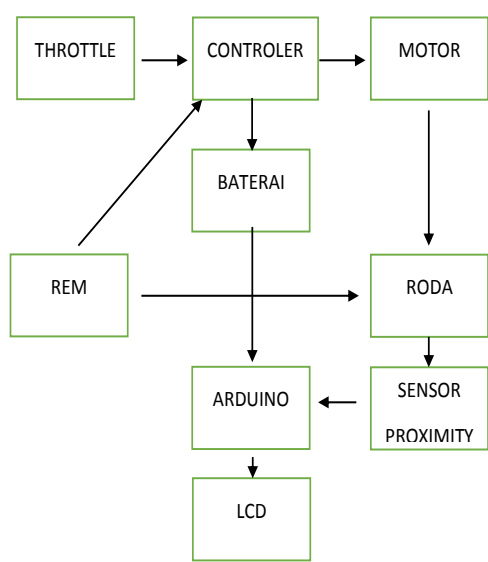

Gambar 2. Diagram Blok

-Throttle : sebagai input controler

- Controler : mengolah data /menggerakkan motor dan mengatur kecepatan motor

-Baterai : supply daya( 240 volt/ 25 )

-Motor : motor yang mengubah energi listrik searah menjadi mekanis yang berupa tenaga penggerak roda

-Rem : ketika rem ditarik controler memerintahkan motor untuk berhenti.

-Sensor proximity : sensor magnetik yang di jepitkan pada ruji roda, untuk membaca gaya mekanik roda

-Arduino : mengolah data dari sensor dn batrai untuk di taampilkan pada lcd.

- LCD : sebagai output.

Untuk mengukur kecepatan dan daya baterai pada sepeda motor listrik 250W menggunakan komponen utama meliputi baterai, kontroler, BLDC, throttle, power meter DC, , dan LCD. , throttle untuk mengendalikan kecepatan sebagai variabel yang dikontrol. Power meter DC dan speedometer untuk mengukur tingkat kecepatan sebagai variabel yang dikontrol terhadap variabel terikat yangmempengaruhi arus, tegangan,daya, energi. LCD untuk menampilkan data dari variabel terikat seperti arus, tegangan, daya, energi dan kecepatan.

\section{Hasil Dan Pembahasan}

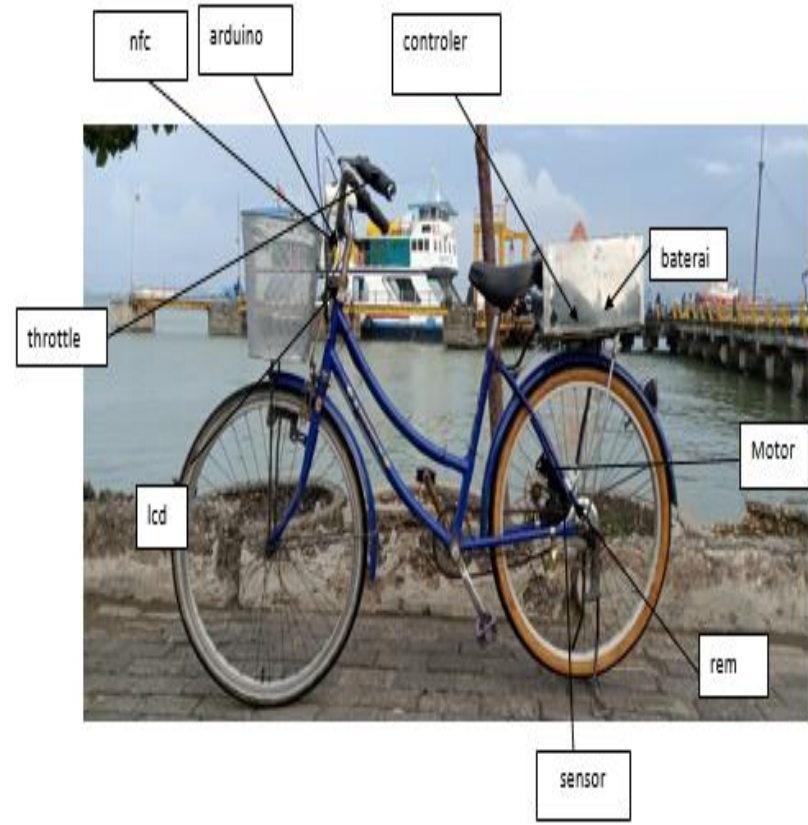

Gambar 3. Desain Sepeda Listrik 250 Watt

Sepesifkasi sepeda listrik

- $\quad$ Sepeda

- $\quad$ Baterai $250 \mathrm{~W} 24$ Volt $12 \mathrm{Ah}$

- $\quad$ Throttle

- Controler

- $\quad$ Motor

- $\quad$ Sensor Proximity

- $\quad$ Led

- $\quad$ rc522 RFID Module blue

- $\quad$ Arduio Uno

B. Desain Sistem Keamanan NFC

A. Desain Alat 


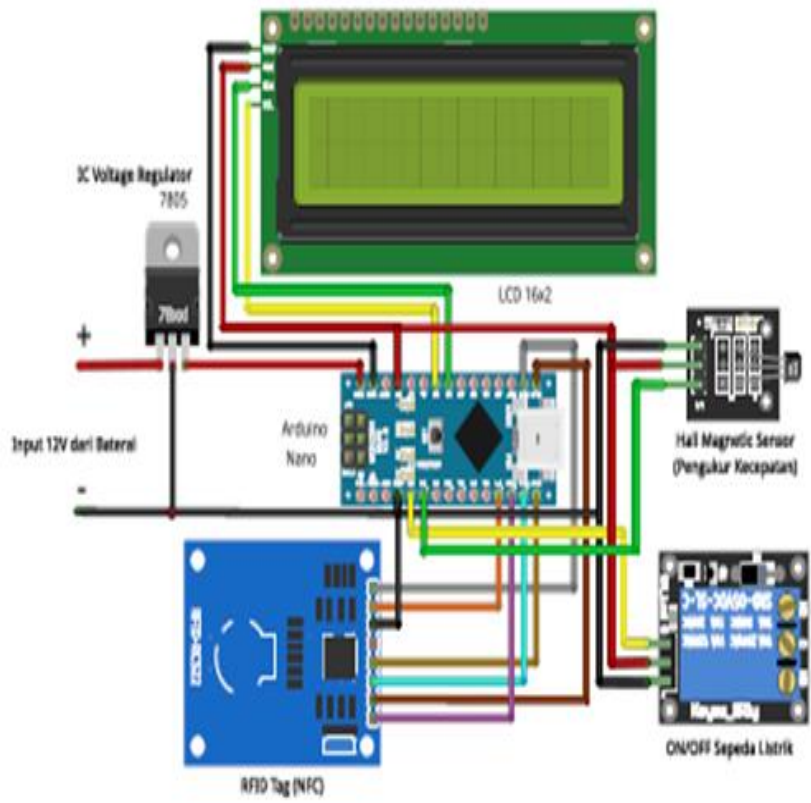

Gambar 4. Skema Sistem Keamanan NFC

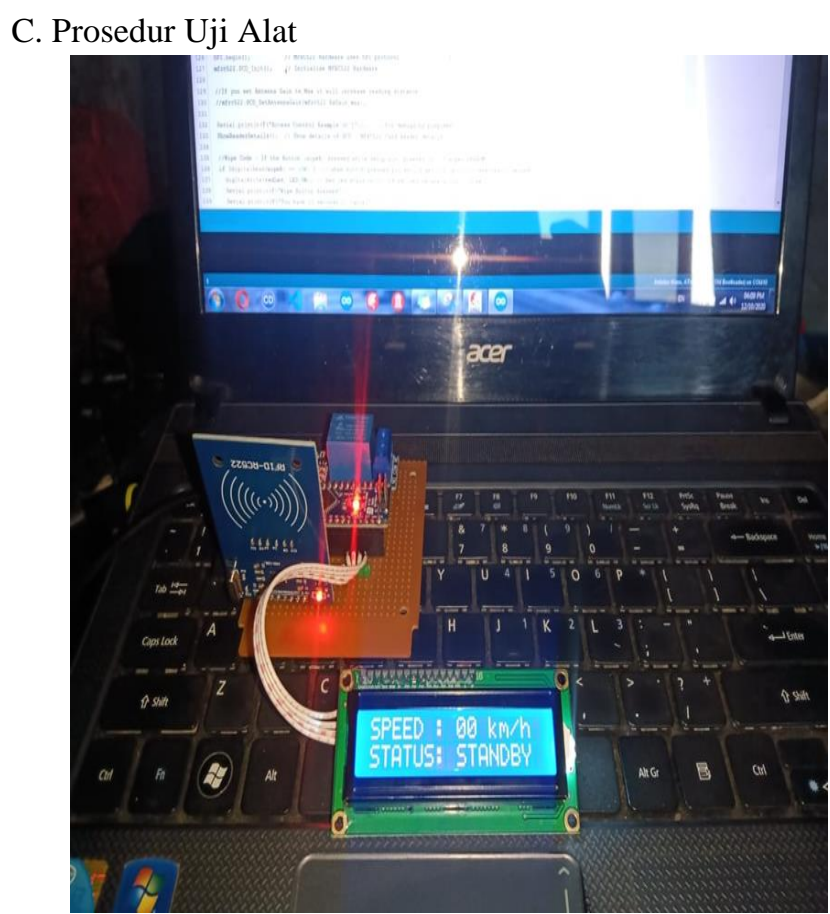

Gambar 5. Uji Sistem NFC 1.aktifkan saklar toggle dikiri box .

2.akan tampil speed (kecepatan) dan status (stand by: menunggu sistem di aktifkan, ready : sistem aktif).

3.tempelkan kartu, maka status akan berubah menjadi ready.

4.sistem telah aktif dan siap digunakan.

Sepeda listrik ini dirancang sistem keamanan menggunakan NFC, jadi hanya pemilik kartu saja yang dapat mengoprasikan sepeda listrik tersebut. ID yang terdapat dalam kartu akan dideteksi leh NFC, selanjutnya outputnya akan di tampilkan melalui LCD, jika pada status LCD menunjukkan ready, maka sepeda siap di gunakan.

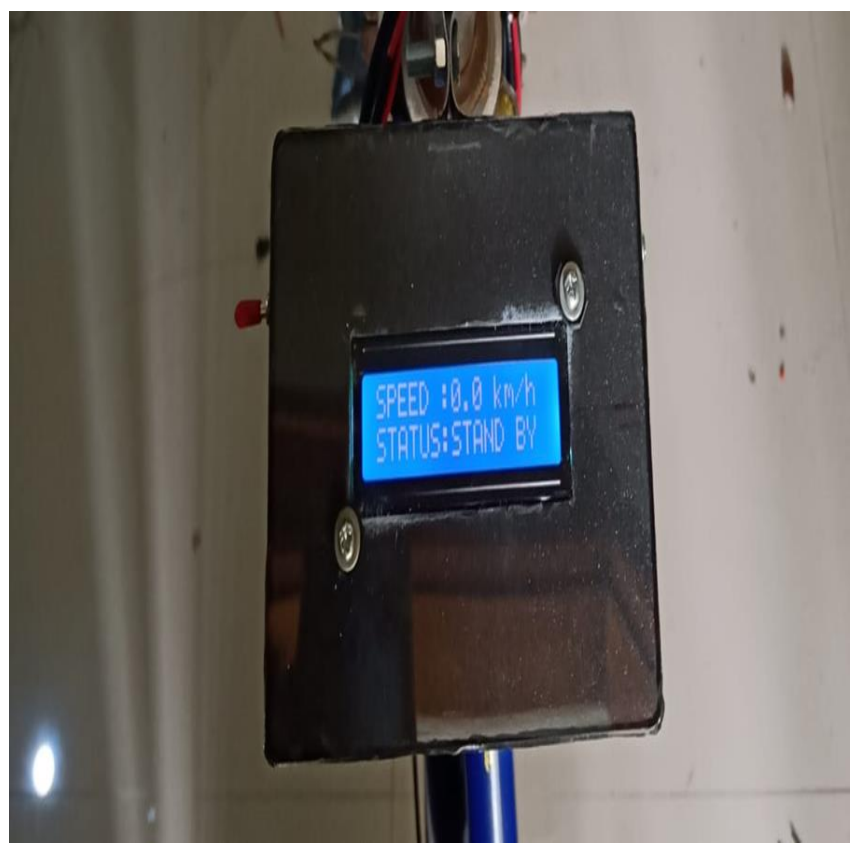

Gambar 6. Output Tampilan LCD

Setelah sepeda listrik sudah menunjukkan status "ready", akan dilanjutkan prosedur pengoprasian sepeda listrik, dimulai dengan Throttle yang berfungsi mengatur kecepatan motor sekaligus sebagai inputan untuk controller. Ketekika data sudah masuk, controller akan mengolah data tersebut untuk mengatur kecepatan motor. motor yang mengubah energi listrik searah menjadi mekanis yang berupa tenaga penggerak roda, disinilah nanti Sensor proximity akan di letakkan pada ruji roda, untuk membaca gaya mekanik roda. Data yang hasilkan oleh sensor akan di olah Arduino mengolah data dari sensor untuk di taampilkan pada lcd secara realtime. 


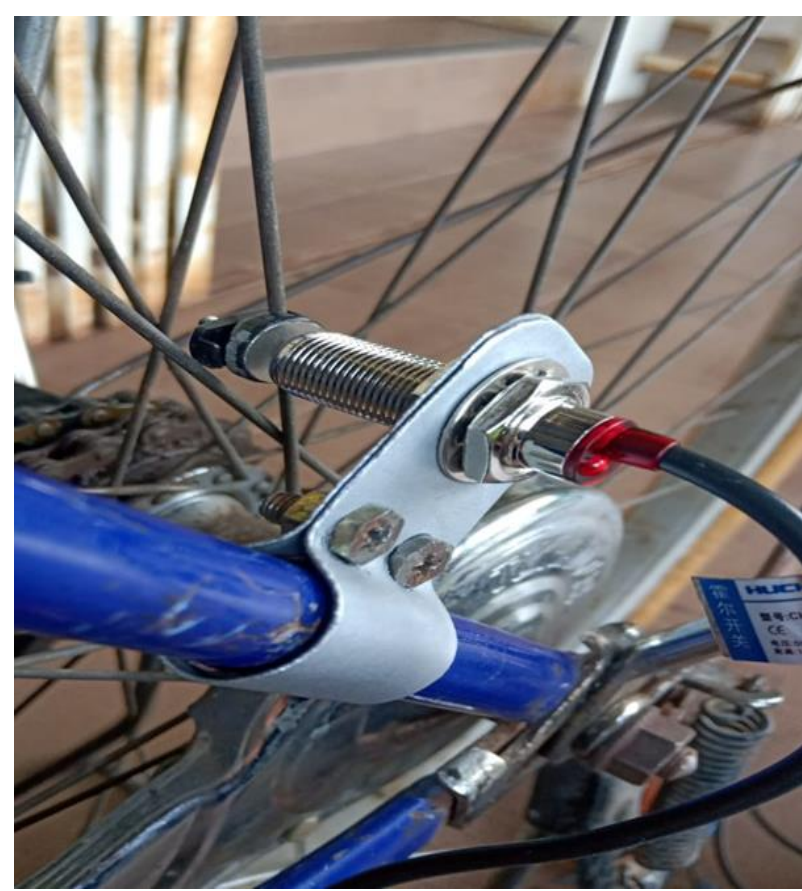

Gambar 7. Sensor Proximity

D. Hasil pengujian

Tabel 1 Hasil Pengujian

\begin{tabular}{|c|c|c|c|c|}
\hline NO & $\begin{array}{c}\text { KECEPATANRATA } \\
\text { RATA }\end{array}$ & $\begin{array}{c}\text { KECEPATAN } \\
\text { MAKSIMAL }\end{array}$ & JARAK TEMPUH & DURASI \\
\hline 1. & $18 \mathrm{Kmph}$ & $25 \mathrm{Kmph}$ & $3.72 \mathrm{~km}$ & 12 menit \\
\hline 2. & $8 \mathrm{Kmphh}$ & $23 \mathrm{Kmph}$ & $1.86 \mathrm{~km}$ & 12 menit \\
\hline $\mathrm{K}$ & $12 \mathrm{kmph}$ & $22 \mathrm{kmph}$ & $1.57 \mathrm{~km}$ & 7 menit \\
\hline 4. & $7 \mathrm{kmph}$ & $17 \mathrm{kmph}$ & $0.08 \mathrm{~km}$ & 1 menit \\
\hline 5. & $9 \mathrm{kmph}$ & $24 \mathrm{kmph}$ & $0.24 \mathrm{~km}$ & 1 mmenit \\
\hline 6. & $13 \mathrm{kmph}$ & $18 \mathrm{kmph}$ & $0.29 \mathrm{~km}$ & 1 menit \\
\hline 7. & $11 \mathrm{kmph}$ & $18 \mathrm{mphh}$ & $0,27 \mathrm{~km}$ & 1 menit \\
\hline 8. & $18 \mathrm{kmph}$ & $23 \mathrm{kmph}$ & $3.33 \mathrm{~km}$ & 9 menit \\
\hline 9. & $7 \mathrm{kmph}$ & $17 \mathrm{kmph}$ & $0,08 \mathrm{~km}$ & 1 ment \\
\hline 10 & $9 \mathrm{kmph}$ & $24 \mathrm{kmph}$ & $0.24 \mathrm{~km}$ & 1 menit \\
\hline
\end{tabular}

Pada pengujian sepeda didapatkan tabel hasih uji diatas, sepeda listrik yang dirancang memiliki kecepatan maksimal $25 \mathrm{kmph}$, pada sampel diatas dengan kecepatan rata rata 18kmph mampu menempuh jarak $3.72 \mathrm{~km}$ dengan waktu 12 menit. Hasil ini didapat dengan kondisi permukaan jalan rata.

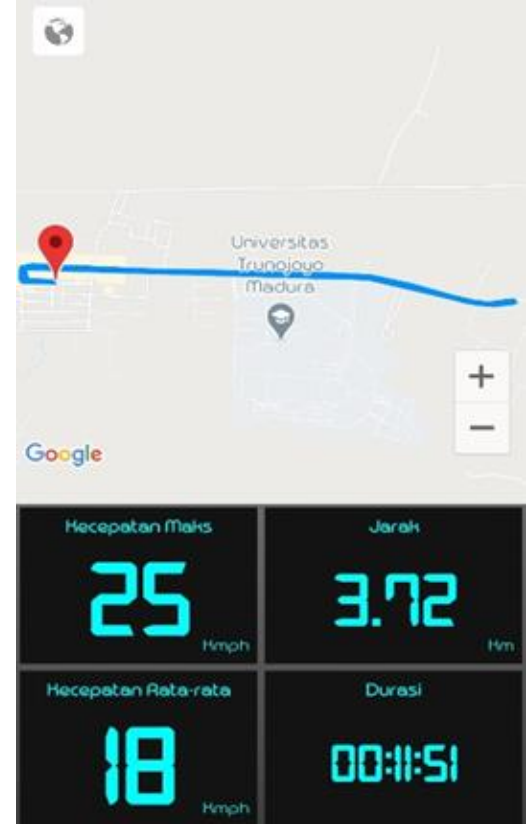

Gambar 8. Hasil Uji

Pada sampel kedua didapatkan data dengan kecepatan maksimal $23 \mathrm{kmph}$, dengan kecepatan rata rata 8kmph mampu menempuh jarak $1,86 \mathrm{~km}$, dengan waktu tempuh yang sama 12 menit.
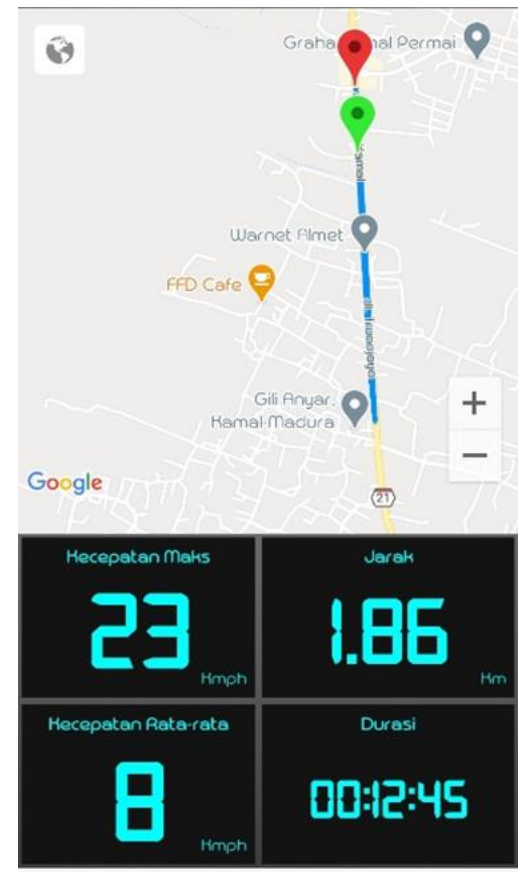

Gambar 9. Hasil Uji 
Dari dua sampel di atas dapat di lihat dengan durasi yang hampir sama memiliki kecepatan dan jarak tempuh yang jauh berbeda. Sampel 1 dengan durasi 12 menit mampu menempuh jarak 3,72 km dengan kecepatan rata rata $18 \mathrm{kmph}$, sedangkan sampe kedua dengan durasi 12 menit hanya menempuh jarak $1,86 \mathrm{~km}$ dengan kecepatan rata rata $8 \mathrm{kmph}$.

Perbandingan sampel hasil uji diatas dapat di analisa bahwa kondisi permukaan jalan sangat mempengaruhi tingkat kecepatan dan jarak tempuh.

Pada kondisi permukaan jalan yang tidak rata lebih lambat dibanding jalan yang mendatar rata.

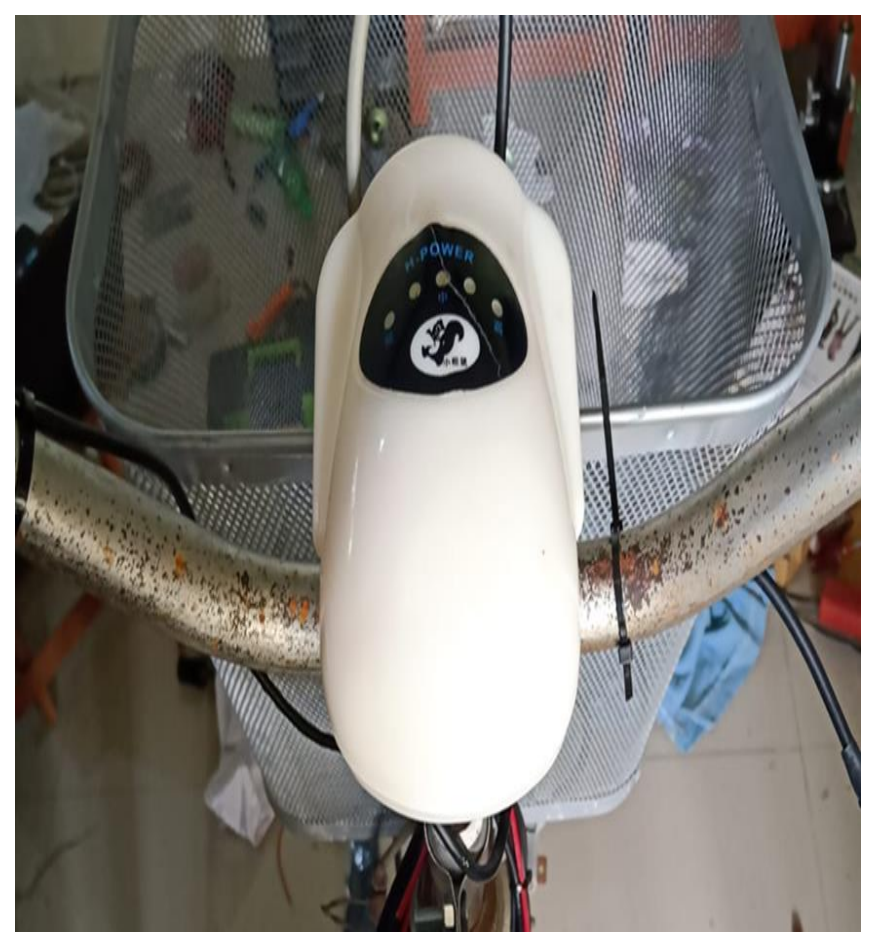

Gambar 10. Indikator Baterai

\section{Kesimpulan}

Berdasarkan penelitian yang telah dilakukaan maka dapat ditarikbeberapa kesimpulan:

a. Kecepatan maksimal sepeda listrik $25 \mathrm{kmph}$

b. kondisi permukaan jalan sangat mempengaruhi tingkat kecepatan dan jarak tempuh. Pada kondisi permukaan jalan yang tidak rata lebih lambat dibanding jalan yang mendatar rata.
Saran

Berdasarkan penelitian yang telah dilakukan, penulis mempunyai saran untuk penelitian selan jutnya supaya alat sepeda listrik bisa stabil pada kondisi jalan apapun.

\section{Daftar pustaka}

Daftar pustaka mengikuti format IEEE seperti terlihat di bawah ini. Untuk memudahkan sangat dianjurkan untuk menggunakan Endnotes Program ataupun Mendelay di dalam mengatur daftar pustaka.

[1] B. Nainggolan, F. Inaswara, G. Pratiwi, and H. Ramadhan, "Rancang Bangun Sepeda Listrik Menggunakan Panel Surya Sebagai Pengisi Baterai,"

[2] D. Satria, R. Lusiani, I. Rosyadi, and A. Fauzi, "ANALISA PERHITUNGAN ENERGI LISTRIK PADA SEPEDA," vol. 11, no. 1, pp. 9-19,

[3] D. Dahlan, D. L. Zariatin, and N. Wibowo, "Perancangan Sistem Pemantauan Kecepatan dan Pengelolaan Baterai pada Sepeda Motor Listrik 3 kW," pp. 366-372.

[4] O. B. Murdianto, I. I. Nyoman, M. Sc, and D. Ph, "Pengembangan Model ' Regenerative Brake' pada Sepeda Listrik untuk Menambah Jarak," vol. 1, no. 2, 2012.2017.Politeknologi, 2016. 
[5] dony kurnia Aji, "Sistem Pengaman Sepeda Motor Dengan Kombinasi Tombol Menggunakan Teknologi Android

[6] K. Joni, A. F. Ibadillah, P. Studi, T. Elektro, F. Teknik, and U. T. Madura, "Rancang Bangun Alat Penetas Telur Ayam Otomatis Dengan Metode PID ( Proportional Integral Derivative ) Berbasis Energy Hybrid."

[7] A. K. Saputro and A. Karim, "MARKOV MODEL," no. 1, pp. 5-7.

[8] K. A. Wibisono et al., "Deteksi Kualitas Tembakau Madura Berbasis Image Processing Dan Sensor Gas."

[9] B. Sumantri, A. Abimayu, and B. Aceh, "Jurnal Rekayasa Elektrika," vol. 14, no. 36, 2018, doi: 10.17529/jre.v14i3.11826.Berbasis Arduino Bluetooth," 2018.

[10] H. Putra, S. Jie, and A. Djohar, “"، PERANCANGAN SEPEDA LISTRIK DENGAN MENGGUNAKAN MOTOR DC SERI “ Key Words: Electric Bike , Designing, DC series Motor, DC permanent magnet Generator." 